\title{
A Study on Theme Activities during School Year and Graduation Season in University Library
}

\author{
Xuefei Yu \\ Department of library, Harbin University of Commerce, Harbin, Heilongjiang, China \\ yuxuefei83@163.com
}

Keywords: library, school year, graduation season.

\begin{abstract}
This paper introduces various theme activities carried out in our university in school year and graduation season based on the rule of library - technical support service, research promote development. At the same time, in view of the current situation of our library, this paper discusses how to develop the theme service of above two quarter in the environment of rapid development of information technology and further promote the construction of cultural activities.
\end{abstract}

\section{Introduction}

Higher education should focus on quality education and cultivate talents that meet the needs of society is the ultimate goal of the major universities. Meanwhile teaching students to take the initiative to learn is the key. Due to semi socialized environment of universities, the classroom teaching has a certain degree of deficiency in cultivation of students' ability. Therefore, in order to make our university education more effective, university library in cultivation of college students' autonomous learning ability has become a pivotal role and can not be underestimated.

\section{Research on theme activities in school year and graduation season}

\subsection{The significance of university library carries out theme activities in school season and graduation season}

As one of the three pillars of running a university, university library, which provides a steady stream of information support for teaching and scientific research, is also responsible for cultivating college students' autonomous learning ability [1]. After entering University, because the learning and living environment change greatly, many college students impacted by family environment and exam oriented education can't adapt to a certain extent especially reflected in school year and graduation season $[2,3]$. In school season, the freshmen who have just start university life feel very fresh to unfamiliar environment, but when the fresh feeling is gone, it will be replaced by emptiness and confusion. In graduation season, many college students are not ready to face the dual pressures of employment and graduation, so that they become anxious. The reason is mainly due to lack of independent learning ability. Many college students do not know how to study in college, where to get new information, in this case they wasted a lot of time and also missed opportunities. The university library create a good learning atmosphere and learning space, and possess a variety of literature resources and tools, and is equipped with modern network. At the same time, there are a number of enthusiasm, capability and selfless librarians. Therefore, university library is able to become the second classroom in training college students to receive professional education and the first classroom in quality training. We can help freshmen and graduates transfer smoothly during those periods and lead them wisely.

\subsection{The current status of university library carries out theme activities in school season and} graduation season

1. School year

The beginning of a new year is a large number of freshmen flush into campus as well as library and the new understanding of school library began. This period is the first step for students to learn how to 
use library. At present, our university library has seized the opportunity to do a lot of work in this time, mainly in the following forms:

(1) Library entrance education of freshmen. After or during the military training, library will contact the relevant departments for organizing freshmen training. The library staff will introduce new students in how to use all kinds of resources, at the same time librarians will issue reader's guidebook, so that readers can read in detail about library layout, departments, functions, book lending system and access to library and so on.

(2) Digital resource awareness month. In order to further cooperate with the freshmen library entrance training and let new students to understand library's electronic resources more quickly, we carried out a digital resources awareness month activity. Through distribute leaflets, quiz, lectures, small gifts and lucky draw, propagandist attract the attention of students in library and answer questions raised by students face to face.

(3) College student retrieval knowledge contest. At the beginning of this year, our library held a contest for college students and in this case we enhance students' enthusiasm to learn retrieval knowledge by the form of competition. Therefore, this activity becomes a good supplement to teacher's teaching and change passive acceptance of knowledge in classroom into initiative to find information they need, so that students improve their information literacy through practice.

2. Graduation season

Graduation season is a time when students focus on writing papers and looking for work so they are much more anxious. Meanwhile, students have a strong sense of sadness because the leaving date is coming. Therefore, this period is the time for students eager to get help and find emotional expression. We have done a lot of work as followings:

(1) Library digital resources retrieval and thesis writing instruction. In order to help students successfully completed graduation thesis and use digital resources rapidly and accurately, library held retrieval knowledge and writing skills training annually to junior students. The activities help students in paper writing and guarantee them quickly find the available resources.

(2) Graduation wall. In graduation season each year, library will set up a graduation wall, which not only to express deep blessing to graduates, but also provide a space for students to express feelings and blessings. Graduates can show their experience of four years' university life and experience in looking for jobs, but also wish for the future. This activity really set up a communication bridge between graduates and library.

(3) Lending history certificate. In graduation season, library can issue senior student a "borrowing history certificate", which records types and quantities of books that students borrowed from library during four years' university life, arming to leave students a permanent memorial. At the same time, the certificate can also encourage students to keep a good habit of reading after leave school.

\subsection{Some thoughts on theme activities in school year and graduation season}

1. School year. The new students' cognition of library in the first semester decided them how to use library resources. Although at this time we held a variety of training in using digital resources, but those activities mainly concentrated in September and October. At the same time, the training mode of digital resources is mainly represented by the teacher, while the students are in a passive state. In addition, many freshmen have rarely awareness about activities held by library. In view of the above problems, we can consider the following aspects of reform and innovation.

(1) The rationalization of training time in school year. The school year is generally concentrated in early September of each year. During this time, new students are busy at military training, different orientation activities of colleges and social publicity activities. If library carried out digital resources training at this time, one possibility is no time available resulting in training delay; another may be held training but did not get the attention of new students.

Therefore, we can consider avoid the peak time school begins and distribute training activities in the first semester. According to the needs of new students to allocate and enrich training content. For example, in addition to the introduction of library layout, collection, lending regulations and databases usage methods, we can also add library history to establish library humanistic image; 
illustrate library collection characteristics by presenting research situation of different schools; use vivid presentation to demonstrate each step from order books to put them on shelves, which enable students to respect staffs' work and love books.

(2) Self activation system of library card. Although library spent a lot of time and manpower to introduce library paper resources and electronic resources and also held many training activities on database usage methods but there are still many students feel confused in searching data every year. The main reason is that training has taken a single form of teacher indoctrination, so new students lack enthusiasm and initiative to acquire knowledge and many students do not realize the importance of training content. In this case, we can consider link training to library card activation by setting up a simple test or game. Students participating the training can start the test and who pass the test can automatically activate library card. In this way, we can set up a goal to new students and make them learn knowledge actively.

(3) Exhibition space of library humanistic activities. At present, many freshmen basically feel that library is a learning space and reading place. If do not use database, they rarely access to library homepage or pay attention to news on library homepage and lack of attention to various activities held by library currently or in the past so it is not conducive to cultural construction of library. If we can open up an area on homepage presenting all kinds of cultural or educational activities, we can make students broaden their cognition about library and stimulate students' interest to participate in certain activities. Furthermore, this space is also a way to record and save activities carried out by library and easy for readers to read and watch.

(4) Career planning services. Employment rate is an important standard to measure the level of education in universities, so we should not only train the people who are willing to serve society, but also cultivate their ability to serve society. To fulfill the aim, on one hand, it depends on school education, on the other hand, it is necessary to motivate students' initiative and realize independent study. Currently, new students in university unclear about their professional prospects and study direction and some students only know subject name but lack of deep understanding for specific content. Such students have desire to play a subjective initiative, but there is no place to start.

As a resource center and the second class, university library can provide service related to occupation planning, such as explanation of a professional outlook of certain job and help students to set up goals and guide study direction. Meanwhile, by combining library resources we can recommend new students books or resources related to their subject and help them spend four years university life efficiently.

2. Graduation season

University graduation season will basically involves three major themes, one is to write a thesis, and the other is all kinds of activities during graduation period, the last is employment. Although we have carried out activities on the first two aspects, but the form is relatively simple, so we can consider development as the following aspects.

(1) The training of citation tools used in paper writing.

The graduation thesis is an examination way of students' professional level and comprehensive ability in university life. In addition to communication between students and their tutor about thesis content and topic, students spend most of their time in searching literature and modification of the above. In this period, we also organized thesis writing guidance training to help students find the information needed. Furthermore, library can consider further enrich training content, adding citation tool used in training, such as the international standard citation tool EndNote introduction or the NoteFirst software purchased. In the process of writing, students need to retain a large number of literature and quoted in article, so how to classify and cite those documents quickly and how to automatically clean up reference list when change article content become essential. The application of these techniques can greatly shorten students' writing time and avoid disadvantages of manual sorting of references. 
(2) Book delivery activities.

After four years of study, graduates have accumulated a large number of various types of books or notes, some of which can not be taken away resulting in a waste of resources. Libraries can create a platform that can be reused for such resources, such as holding a book donation or delivery. Graduates can donate unneeded books or notes to library, or in other case, library can exchange those resources for bookmarks with library logo. After the first trial recycling, the recycled paper resources can be putted on shelves and placed in obvious position for other students to read. This will not only improve utilization of resources, but also cultivate a good atmosphere of unity and mutual assistance.

(3) Recommended activities for graduates.

In order to enhance book loan quantity, various reading promotion activities were conducted in our library, which achieved good results. In graduation season, we could consider to bring graduates into book recommendation. Graduates who experience four years of university time have similar hobbies and living environment with undergraduates. Books recommended by graduates likely spark sympathies of undergraduates enhancing the book loan quantity.

(4) Lifelong reader system.

The cultivation of college students by universities should not be confined within four years. Graduates who step into society rely much on information resources. In this case, as their old school, we should do our best to help them and further provide information to them. Therefore, we could consider establish a lifelong reader system. In this system, graduates can come back to the library to get information they need free of charge. Readers who need library services can get permissions of accessing electronic resources outside the university. This kind of humanized service can help graduates solve problems of getting useful information hardly.

\section{Conclusion}

In conclusion, the views that I've been sketching above are some humble opinions. There must be some deficiencies and areas to further open to question. I hope we can make full use of these two periods. Readers who come to library are not only for learning space, but also for the various resources and service that we provide. One of our aims is to further promote the construction of humanistic spirit and cultivate students' ability of autonomous learning.

\section{Acknowledgments}

This work was financially supported by Doctoral Research Foundation of Harbin University of Commerce.

\section{References}

[1] N. P. Lei, Talking about the innovative service of the libraries of application-oriented universities and colleges of undergraduate course, Sci-Tech Information Development and Economy. 22 (2009) 36-37.

[2] H. M. Zhu, M. X. Shu, Analysis on theme activities of freshmen in the applied university of undergraduate, Journal of Chuzho University. 06 (2014) 133-136.

[3] J. Z. Wu, A preliminary study on cultural activities of college graduation season, The library journal of Henan. 03 (2014) 65-67. 